\title{
1 Substrate ligand density modulates gap junction intercellular communication 2 during mesenchymal cell condensation
}

3 Ignasi Casanellas ${ }^{\mathrm{a}, \mathrm{b}, \mathrm{c}}$, Anna Lagunas ${ }^{\mathrm{c}, \mathrm{a} *}$, Yolanda Vida ${ }^{\mathrm{d}, \mathrm{e}}$, Ezequiel Pérez-Inestrosa ${ }^{\mathrm{d}, \mathrm{e}}$, Cristina Rodríguez-

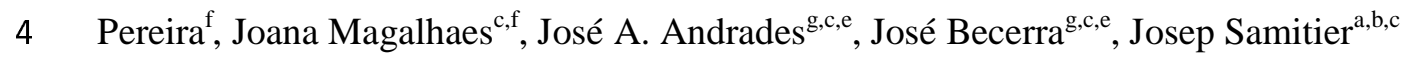

$6{ }^{a}$ Institute for Bioengineering of Catalonia (IBEC), Barcelona Institute of Science and Technology (BIST). c/ Baldiri

7 Reixac, 10-12, 08028 Barcelona, Spain.

$8 \quad{ }^{b}$ Department of Electronics and Biomedical Engineering, University of Barcelona (UB), Faculty of Physics. c/ Martí

9 i Franquès, 1, 08028 Barcelona, Spain.

$10{ }^{\mathrm{c}}$ Biomedical Research Networking Center in Bioengineering, Biomaterials, and Nanomedicine (CIBER-BBN). Av.

11 Monforte de Lemos, 3-5. Pabellón 11. Planta 0, 28029 Madrid, Spain.

12 deniversidad de Málaga - IBIMA, Dpto. Química Orgánica. Campus de Teatinos s/n, 29071 Málaga, Spain.

$13{ }^{\text {e }}$ Centro Andaluz de Nanomedicina y Biotecnología-BIONAND. Parque Tecnológico de Andalucía, c/ Severo Ochoa 14 35, 29590 Campanillas, Málaga, Spain.

15 fUnidad de Medicina Regenerativa, Grupo de Investigación en Reumatología (GIR), Instituto de Investigación

16 Biomédica de A Coruña (INIBIC), Complexo Hospitalario Universitario de A Coruña (CHUAC), Sergas,

17 Universidade da Coruña (UDC). c/ Xubias de Arriba, 84, 15006 A Coruña, Spain.

$18{ }^{\mathrm{g}}$ Department of Cell Biology, Genetics and Physiology, Universidad de Málaga (UMA), Instituto de Investigación 19 Biomédica de Málaga (IBIMA). Av. Cervantes, 2, 29071 Málaga, Spain.

$20 *$ Corresponding author: alagunas@ibecbarcelona.eu

22 Abstract

23 Gap junction intercellular communication (GJIC) provides a continuous and efficient flow of biological 24 information during tissue formation and is essential to sustain homeostasis and function in living 25 organisms. Cell-matrix interactions have been widely addressed and their influence on tissue organization 26 is recognized. However, how extracellular matrix (ECM) adhesion affects intercellular communication 27 during tissue formation remains elusive. Here we use substrates with uneven nanopatterns of adhesive 28 ligand arginine-glycine-aspartic acid (RGD) to control cell adhesion during mesenchymal condensation, a 29 prevalent morphogenetic transition. We show that the establishment of GJIC is an adhesion-gated mechanism, which is dynamically regulated. Substrate effects continuously propagate into the forming tissue through actomyosin contraction, affecting both the 3D architecture and functionality of the GJIC

34 Keywords: Dendrimer-based nanopatterning, arginine-glycine-aspartic acid (RGD), cell adhesion, mesenchymal stem cells (MSCs), condensation, gap junction intercellular communication (GJIC). 


\section{Introduction}

Mesenchymal cell condensation is a prevalent morphogenetic transition regulated by cell adhesion in which mesenchymal stem cells (MSCs) gather to form intimate cell-to-cell contacts [1]. The condensation phase was named "membranous skeleton" by Grüneberg to stress its distinctive function in skeletal development [2]. During skeletogenesis, cell density increases locally at the condensation sites by means of extracellular matrix (ECM)-driven active cell movement, ${ }^{1}$ with an important role of the ECM ubiquitous protein fibronectin (FN), which is upregulated during mesenchymal condensation [3,4]. Cell condensates progressively evolve into cartilaginous nodules, setting the bases for cartilage formation.

In osteochondral development, mesenchymal cell condensation is concurrent with the formation of an extensive gap junction (GJ) communication network [5]. GJs are plasma membrane channels that provide intercellular and cell-matrix communication in almost all animal tissues, allowing cells to exchange ions and small molecules through a controlled gating mechanism [6]. During morphogenesis, an efficient network of GJs is an extremely versatile communication system that mediates the rapid synchronization between cells. GJs established during embryonic patterning allow multicellular groups to coordinate towards the formation of supracellular, tissue-level structures. Avascular tissues, such as cartilage, particularly rely on this form of intercellular communication for successful development [7-9].

Although previous studies have related gap junction intercellular communication (GJIC) with matrixassociated proteins [10-13], little is known about how extracellular inputs modulate the formation of intercellular GJ networks and the associated implications in tissue architecture and function. Integrinmediated cell-matrix interactions have been shown to regulate many biological processes such as cell shape, proliferation, migration, differentiation and programmed cell death [14-16]. During morphogenesis, dynamic adhesion mechanisms, together with the associated regulatory signalling pathways, define tissue differentiation and architecture, and modulate collective cell behaviour [17-19]. Cell adhesion is governed at the nanoscale, as evidenced by the assembly of collagen fibres in the ECM or the folding/unfolding of fibronectin [20-22], and also by the compartmentalization of the cell membrane receptors into nanoclusters, which facilitates the allosteric regulation, increases the ligand rebinding probability and triggers the assembly of signalling complexes in the cytosol [23]. The nanopatterning of ECM motifs for the study of cell-surface interactions at the nanoscale highlighted the relevance of ECM ligand presentation to cells. Experiments using micellar lithography to create nanopatterns of the cell adhesive peptide arginine-glycine-aspartic acid (RGD) of fibronectin (FN), unveiled a nanospacing threshold of around $70 \mathrm{~nm}$ for an efficient cell adhesion on stiff substrates, and 
[24-27]. Since these first works in the field, others have emerged showing that not only cell adhesion, but also many other cell responses are affected by the nanoscale ligand presentation [28]. In previous works, we have shown that a dendrimer-based RGD nanopatterning technique produces uneven nanopatterns of tuneable local surface adhesiveness with liquid-like order and defined spacing on

73 large areas, thus being fully compatible with standard cell culture protocols [29]. Owing to steric

74 hindrance restrictions, each dendrimer of 4-5 $\mathrm{nm}$ in diameter, although bearing up to eight copies of the RGD ligand, provides a single site for integrin receptor binding. Therefore, dendrimer nanopattern configuration directly correlates with the RGD available for cell adhesion. The local surface adhesiveness in the nanopatterns is obtained by quantifying the percentage of surface area with a minimum interparticle distance below the $70 \mathrm{~nm}$ threshold for an efficient cell adhesion. These nanopatterns proved to sustain cell adhesion more efficiently than the corresponding homogeneous surfaces [29] and improve cell differentiation [30-32].

Taking chondrogenesis as a model [33], we used the RGD dendrimer-based nanopatterns to conduct a systematic study of the influence of local surface adhesiveness on the establishment of GJIC network during mesenchymal 3D condensation. Results show that local surface adhesiveness triggers cell condensate responses from a threshold nanopattern configuration and we demonstrate that the adhesive substrate information, which is transduced by integrins, propagates within cell condensates in a

\section{Methods}

\subsection{Production of nanopatterned substrates}

All steps were performed in a sterile tissue culture hood, and only sterile materials, solutions and techniques were used. All dendrimer solutions were sonicated and filtered through a Millex RB sterile syringe filter (Merk Millipore) prior to use, and stock solutions were used within 6 months of preparation. Nanopatterned substrates were prepared as previously described [30,31]. Briefly, a 95/5 L-lactide/DLlactide copolymer (Corbion) 2\% $\mathrm{m} \mathrm{v}^{-1}$ solution in dry 1,4-dioxane (Sigma-Aldrich, 296309) was spincoated at $3000 \mathrm{rpm}$ for $30 \mathrm{~s}$ on $1.25 \times 1.25 \mathrm{~cm}$ Corning ${ }^{\circledR}$ glass microslides (Sigma-Aldrich). Deionized water (18 M $\Omega \cdot \mathrm{cm}$ Milli-Q, Millipore) was used for rinsing samples and to prepare RGD-functionalized dendrimers' working solutions at $2.510^{-8}, 10^{-8}$ and $410^{-9} \% \mathrm{w} \mathrm{w}^{-1}$ concentrations. Spin-coated on poly(Llactic acid) (PLLA) substrates were treated for 13 min under UV light and immersed in dendrimer solutions for $16 \mathrm{~h}(\mathrm{pH}=5.6, \mathrm{~T}=293 \mathrm{~K})$. Then, the nanopatterned substrates were rinsed with copious 
102

103

104

105

106

107

108

109

110

111

112

113

114

115

116

117

118

119

120

121

122

123

124

125

126

127

128

129

130

131

132

133

134

amounts of water and dried. Positive controls $\left(\mathrm{S}_{\mathrm{FN}}\right)$ were obtained by incubating spin-coated PLLA substrates with fibronectin $\left(100 \mu \mathrm{g} \mathrm{mL}^{-1}\right)$ from bovine plasma-solution (Sigma-Aldrich, F1141). Nanopatterned substrates were imaged by atomic force microscopy (AFM) in a Dimension 3100 AFM instrument (Veeco Instruments) operated in tapping mode at room temperature in air. Silicon AFM probes (Budget Sensors) with a spring constant $\mathrm{k}=40 \mathrm{~N} \mathrm{~m}^{-1}$ and a resonant frequency $v=300 \mathrm{kHz}$ were used. At least three images of $5 \times 5 \mu \mathrm{m}$ were taken per substrate of three independent substrates per condition (initial dendrimer concentration in solution). The AFM height images were processed with WSxM 4.0 software [34]. Corresponding image thresholds were obtained manually and processed with ImageJ software (NIH). The resulting particle positions were used to obtain the minimum interparticle distances $\left(\mathrm{d}_{\text {min }}\right)$ using a custom-generated MATLAB code (The MATHWORKS, Inc.), and the corresponding probability contour plots for $d_{\text {min }}$ were constructed using an adapted MATLAB code [29]. At least three images from independent samples were computed. Quantification of the percentage of the area with a $\mathrm{d}_{\min }$ threshold below $70 \mathrm{~nm}$ in the $d_{\min }$ probability contour plots was performed by manually selecting the regions and processing them with ImageJ.

\subsection{Cell culture}

Human adipose-derived MSCs (ATCC, PCS-500-011) were cultured at $37^{\circ} \mathrm{C}$ and $5 \% \mathrm{CO}_{2}$ in $\mathrm{MSC}$ Basal Medium (ATCC, PCS-500-030) supplemented with MSC Growth Kit Low Serum (ATCC, PCS-500040). Medium was replaced every 2 days. Passaging was carried out when cells reached 70-80\% confluence. For the experiments, cells were trypsinized at passages 3 to 4 , counted, resuspended in chondrogenesis-inducing medium Chondrocyte Differentiation Tool (ATCC, PCS-500-051) with 0.1\% v $\mathrm{v}^{-1}$ penicillin-streptomycin (Invitrogen, 15140), and seeded on nanopatterned and control substrates at a density of 2,760 cells $\mathrm{cm}^{-2} .3$ replicates of each condition were seeded. Medium was replaced every 3 days.

\subsection{Immunostaining}

After 6 and 9 days of chondrogenic differentiation on the nanopatterns and controls, cells were carefully rinsed with PBS (Gibco, 21600-10), fixed with Formalin Solution (Sigma, HT5011) for 20 min at room temperature, and rinsed again twice with PBS. Aldehyde groups were blocked with $50 \mathrm{mM}$ ammonium chloride (Sigma, A9434) in PBS for 20 min. Samples were permeabilized with saponin (Sigma, 47036) $0.1 \% \mathrm{~m} \mathrm{v}^{-1}$ in BSA (Sigma, A3059) $1 \% \mathrm{~m} / \mathrm{v}$ in PBS for $10 \mathrm{~min}$. 
For connexin $43(\mathrm{Cx} 43)$ and cell nuclei observation in cell condensates, samples were stained with rabbit anti-Cx43 (Abcam, ab63851) antibody at $5 \mu \mathrm{g} \mathrm{mL}^{-1}$ in BSA $1 \% \mathrm{~m} \mathrm{v}^{-1}$ in PBS for $1 \mathrm{~h}$ at room temperature, then with anti-rabbit Alexa 568 (LifeTech, A11036) and Hoechst (Invitrogen, H3570) $1 \mu \mathrm{g} \mathrm{mL}^{-1}$ in BSA $1 \% \mathrm{~m} \mathrm{v}-1$ in PBS for $1 \mathrm{~h}$. Samples were prepared with coverslips in Fluoromount mounting medium (Sigma, HT5011).

\subsection{Image acquisition and analysis}

Samples were imaged with a Leica SPE Upright Confocal Microscope (Leica Microsystems) with a 40x/1.15 NA objective. The distance between imaged slices (z-size) was set at $1 \mu \mathrm{m}$. At least 3 cell condensates were imaged for each sample.

Images were analyzed with ImageJ software. For condensate size measurements, a z-projection of each condensate was created, and the whole condensate area was manually selected and measured. For the measurement of $\mathrm{Cx} 43$ expression confocal z-projections were used (maximum stained area per sample). Briefly, the background of z-projections was removed, and a threshold was applied to select areas of $\mathrm{Cx} 43$ expression. The obtained total area was normalized against the area of the corresponding condensate.

For the analysis of GJIC network, a threshold was applied to the Cx43 confocal stack and then it was skeletonized with the ImageJ plugin (Fig. S1, Video S1). The resulting Cx43 network was analyzed to retrieve the number of end-point voxels and the mean branch length in each condensate, which were normalized to the Cx43 expression area and the number of slices taken for analysis. GJIC was calculated as the inverse value of the end-point voxels.

\subsection{RNA extraction and retrotranscription}

Reverse transcription real-time PCR (RT-qPCR) was performed to measure Cx43 (GJAl) expression. After 6 and 9 days of differentiation, mRNA was extracted from the samples and purified with a RNeasy Micro Kit (Qiagen, 74004). Extracted mRNA was quantified in a Nanodrop ND-1000 Spectrophotometer (Thermo Fisher Scientific). Reverse transcription for cDNA production was performed with an iScript Advanced cDNA Synthesis Kit (Bio-Rad, 1725037) in a T100 Thermal Cycler (Bio-Rad). Three cell culture replicates of each condition were obtained, with their RNA extracted and retrotranscribed. The same procedure was performed on undifferentiated human mesenchymal stem cells (hMSCs) as a reference. 


\section{6. $q$ PCR and data analysis}

qPCR was performed with the Sso Advanced Universal SYBR Green Supermix kit (Bio-Rad, 1725271) in an Applied Biosystems StepOnePlus Real-Time PCR Machine (Thermo Fisher Scientific). Commercial primer pairs were used for GJAl (Bio-Rad, qHsaCID0012977), as well as B2M (Bio-Rad, qHsaCID0015347) and RPL24 (Bio-Rad, qHsaCID0038677) as housekeeping genes. To prevent gDNA amplification, a DNase digestion step was included during RNA extraction and intron-spanning primer pairs were selected. The amplification program consisted of an initial activation step of $30 \mathrm{~s}$ at $95^{\circ} \mathrm{C}$, followed by 50 cycles of $10 \mathrm{~s}$ at $95^{\circ} \mathrm{C}$ for denaturation and $1 \mathrm{~min}$ at $60^{\circ} \mathrm{C}$ for annealing and extension, and a final denaturation step of $15 \mathrm{~s}$ at $95^{\circ} \mathrm{C}$. Melt curves were performed from $65^{\circ} \mathrm{C}$ to $95^{\circ} \mathrm{C}$ in steps of $0.5^{\circ} \mathrm{C}$. Technical duplicates of each sample were performed in the qPCR.

qPCR data were analyzed with qBase+ software version 3.1 (Biogazelle, Zwijnaarde, Belgium). Only samples with a $\mathrm{Ct}$ below 40 were considered for analysis. The expression of each gene was calculated by the $2^{-\Delta \Delta C t}$ method, normalized to that of undifferentiated hMSCs (assigned value 1) and presented as relative mRNA expression levels.

\subsection{Neurobiotin (NB) assay}

A tracer assay was performed to analyze the functionality of GJIC networks. Three replicates of each condition were seeded in chondrogenesis-inducing medium, as described above. After 6 days of differentiation, samples were washed with HBSS buffer without calcium or magnesium (Life Technologies, 14175095) and treated with neurobiotin $2 \% \mathrm{~m} \mathrm{v}^{-1}$ (Vector, SP-1120) in HBSS for $90 \mathrm{~s}$ at $37^{\circ} \mathrm{C}$. Samples were then washed with HBSS, fixed with Formalin Solution, permeabilized with saponin and stained with Streptavidin-Texas Red conjugate (Life Technologies, S872) and Hoechst $1 \mu \mathrm{g} \mathrm{mL}^{-1}$ in BSA $1 \% \mathrm{~m} \mathrm{v}^{-1}$ in PBS for $1 \mathrm{~h}$ at room temperature. Samples were imaged with a Leica SPE Upright Confocal Microscope as described above.

Images were analyzed with ImageJ software. A z-projection of each condensate was created, and background was removed. Distance of neurobiotin spread was measured in a straight line from the outer rim of the condensates' inwards, in at least two separate locations for each condensate.

\subsection{Condensate transplantation assay}

Nanopatterns with $18 \%\left(\mathrm{~S}_{18}\right)$ and $90 \%\left(\mathrm{~S}_{90}\right)$ of local surface adhesiveness were used (Fig. S2 and Table S1). A transplantation assay was performed to study the effects of RGD nanopatterned substrates on 
203

204

205

206

207

208

209

210

211

212

213

214

215

216

217

218

219

220

221

222

223

224

225

226

227

228

229

230

231

232

233

234

235

\section{4}

formed condensates and the propagation of the adhesive information from the substrate into cell condensates. Cells were cultured on the nanopatterns in chondrogenesis-inducing medium as described above. After 3 days, cell condensates formed on the nanopatterns of $S_{90}$ were removed by pipetting and transferred to new $S_{90}$ or $S_{18}$ substrates. Transplanted condensates were cultured on the new substrates for another 3 days, to a total of 6 days of differentiation. For each sample, around half of the condensates were transplanted, whereas the other half were kept on the original substrate (not transplanted) as a control of unaltered differentiation. Three replicates of each condition were seeded and transplanted.

Samples were fixed, immunostained, imaged and analyzed for Cx43 expression as described above. Results were normalized to those of non-transplanted $S_{90}$ condensates (assigned value 1) and presented as relative values.

To visualize condensates from the side (transversal cuts), Z-stacks were resliced and one image from the center of the condensate was selected. $\mathrm{Cx} 43$ production at the basal and top layers of condensates was measured by the average staining intensity at each region on unprocessed images. For each condensate, average basal intensity was divided by average top intensity to obtain the Basal/Top ratio, indicative of Cx43 distribution within condensates.

\subsection{Integrin blocking and myosin inhibition assays}

Three replicates of each condition were seeded in chondrogenesis-inducing medium as described above. For integrin blocking samples, medium was changed to fresh medium containing RGD dendrimers in solution at $410^{-9} \% \mathrm{w} \mathrm{w}^{-1}$ after 5 days of differentiation. We selected this dendrimer concentration because it yields $\mathrm{S}_{18}$ substrates. During substrate functionalization, equilibrium is reached between dendrimer concentration in solution and adsorbed dendrimer density; hence, use of the concentration corresponding to the substrates with the lowest density prevents further adsorption mid-assay.

For the myosin inhibition experiment, medium was changed to fresh medium with $50 \mu \mathrm{g} \mathrm{mL}{ }^{-1}$ blebbistatin (Sigma, B0560) $6 \mathrm{~h}$ before fixation.

All samples were fixed at day 6 of chondrogenesis, immunostained with anti-Cx43 antibody and SirActin (Tebu-bio, SC001), and imaged with a Zeiss LSM780 Confocal Microscope (Zeiss Microscopy) with a 40x objective. Cx43 expression in condensates was quantified as described above and normalized to corresponding non-treated samples.

\subsection{Statistics}


Quantitative data are displayed, showing average and standard error of the mean (SEM). $\mathrm{n}$ is the sample size. Significant differences were judged using the One-way ANOVA with Fisher LSD post-hoc test or Ttest when only two groups are compared, using OriginPro 8.5 or the Simple Interactive Statistical Analysis (SISA) online tool [35]. Where data did not pass a normality test, a Kruskal-Wallis test with Dunn means comparison was applied with GraphPad Prism 8.3. A $p$ of less than 0.05 was considered statistically significant.

\section{Results}

\subsection{Gap junction intercellular communication: Network architecture and functionality}

We seeded hMSCs on the nanopatterns in chondrogenic medium. Due to the poor interfacing of PLLA with living tissue [36], cells attached preferably through RGD-functionalized dendrimers. Pristine nonpatterned PLLA $\left(\mathrm{S}_{0}\right)$ and FN-coated $\left(\mathrm{S}_{\mathrm{FN}}\right)$ substrates were the negative and positive controls for cell adhesion, respectively. To control the local surface adhesiveness at the nanoscale during mesenchymal condensation, we used nanopatterns with $18 \%\left(\mathrm{~S}_{18}\right)$, 45\% $\left(\mathrm{S}_{45}\right)$ and $90 \%\left(\mathrm{~S}_{90}\right)$ of local surface adhesiveness (Fig. S2 and Table S1). Under chondrogenic stimuli, mesenchymal cells aggregate into three-dimensional condensates. While cells on pristine and nanopatterned substrates immediately start aggregating, cells on fibronectin-coated substrates proliferate and adopt a monolayer configuration, from which a few small condensates develop after 3 to 5 days (Fig. S3A) [30]. Condensates in $\mathrm{S}_{90}$ maintain their structure in culture up to day 14 (Fig. S3B) [37], while condensates in the rest of the substrates progressively collapse, with detached cells adopting a fibroblast-like morphology (Fig. S3C). We measured the distance between adjacent cell nuclei and found that condensates on high-adherence substrates $\left(\mathrm{S}_{90}\right.$ and $\left.\mathrm{S}_{\mathrm{FN}}\right)$ were packed together more tightly than those on low- and mid- adherence ones (Fig. S3D). In the case of large $S_{90}$ condensates, this could be a factor explaining their resistance to collapse through day 14 .

Intercellular communication through gap junctions is crucial for correct cartilage development. We have previously observed increased expression of chondrogenic markers on $S_{90}$ substrates [30]; we thus wondered if ligand density effects could improve cartilage formation beyond individual cell differentiation. To examine cell-cell interconnectivity through GJ formation, we measured $\mathrm{Cx} 43$ in cell condensates. Cx43 is the most widely expressed and studied GJ protein [38] and modulates cartilage structure through its C-terminal cytosolic domain [39]. Connexin hemichannels, or connexons, accumulate and dock with apposed connexons from adjacent cells to form dense GJ plaques. GJIC largely depends on the size of GJ plaques [40] which are continuously regenerated by the addition of connexon 
subunits at the edges and internalization from the center of the plaques [7,41,42]. Such a continuous renewal may ensure the maintenance of the established GJIC network.

We analysed the expression of GJAl at day 6 and 9 of chondrogenesis (Fig. 1A). GJAl was overexpressed on $S_{90}$ to over twice the level of undifferentiated hMSCs at day 6 and reduced by half on $\mathrm{S}_{\mathrm{FN}}$. However, expression on $\mathrm{S}_{90}$ levelled off at day 9 among the different nanopattern configurations and $\mathrm{S}_{0}$. GJAl expression in $\mathrm{S}_{18}$ and $\mathrm{S}_{45}$ nanopatterns is comparable to that of the negative control both at day 6 and 9 of chondrogenic induction.

Cx43 immunofluorescent images show Cx43 assembled in GJ plaques. Quantification of the percentage of immunostained area showed higher values on $S_{90}$ when compared to most other substrates at day 6 and a slight decrease at day 9, mirroring mRNA expression (Fig. 1B). The fact that Cx43 in GJ plaques on $\mathrm{S}_{90}$ is not as high as mRNA expression at day 6 could be explained by a rapid initial turnover [12,41]. Confocal z-projections (Fig. 1C, top) of immunostaining show that Cx43 GJ plaques were roughly distributed within the cell condensates with a tendency to accumulate in the outer cell layers, particularly in $\mathrm{S}_{45}$.

Skeletonization of $\mathrm{Cx} 43$ immunostained images renders a 3D representation of the intercellular communication network (Fig. 1C, bottom, Fig. S1 and Video S1), from which the average branch length (Fig. S4) and number of branch terminations (end-point voxels) can be calculated. Shorter branches and fewer end-point voxels indicate a more intricately shaped GJIC network, as shown in the zoomed-in sections of the skeletonized images of condensates from $S_{90}$ and $S_{0}$ nanopatterns. We thus took the number of branch terminations as the inverse index for $\mathrm{Cx} 43$ architectural connectivity (Fig. 1D). At days 6 and 9 of chondrogenic induction, connectivity progressively increased with local surface adhesiveness up to $S_{90}$ and decreased for $S_{\mathrm{FN}}$.

Observation of the spread of biotinylated or fluorescent tracers has become one of the most common methods of demonstrating gap junctions network coupling [43]. Therefore, to further assess GJIC, we conducted a neurobiotin (NB) tracer uptake assay in cell condensates (Fig. 1E). NB is a GJ/hemichannel permeable dye that can penetrate from the exposed Cx43 connexons and diffuse inwards across the GJIC network when $\mathrm{Ca}^{2+}$ is maintained below physiological levels (open channel conformation). Quantification of NB diffusion into cell condensates showed NB uptake is significantly higher in $\mathrm{S}_{90}$ nanopatterns and equal for all other substrates (Fig. 1F), thereby indicating that $S_{90}$ condensates developed a more efficient GJIC network. 
A

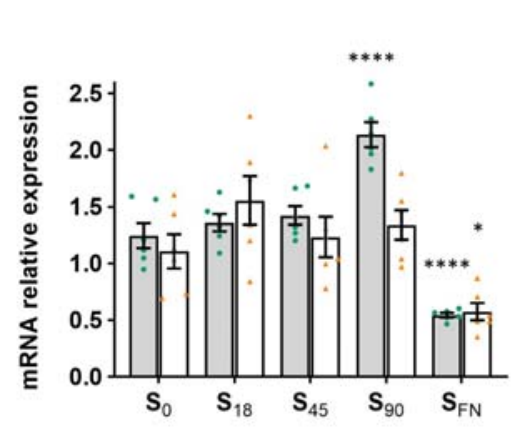

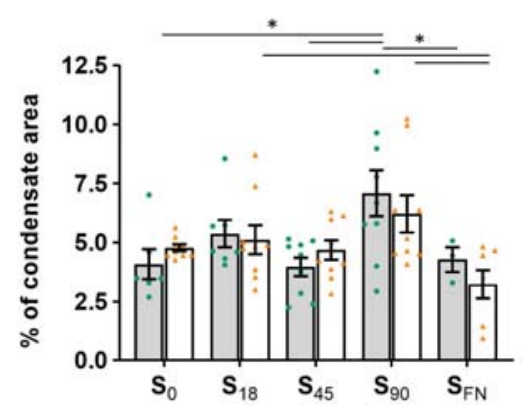

C $\mathrm{S}_{0}$

$\mathrm{S}_{18}$

$\mathbf{S}_{45}$
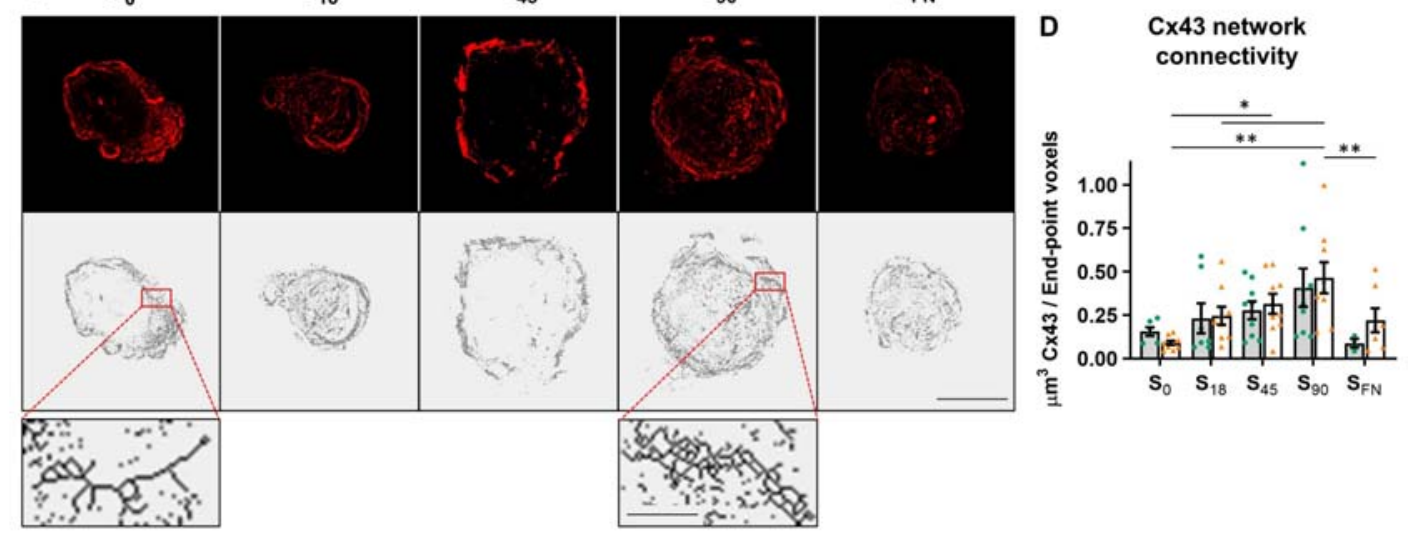

E

$\mathrm{S}_{0}$

$\mathrm{S}_{18}$

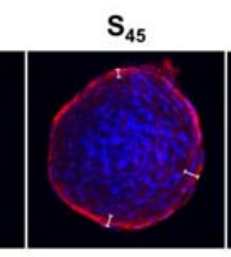

$\mathrm{S}_{90}$

F

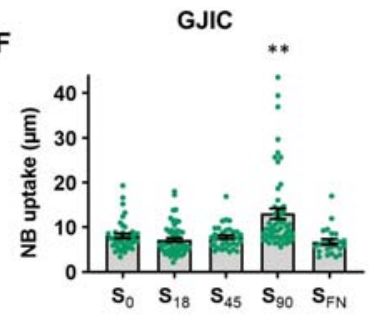

Fig. 1: Ligand density modulates gap junction network architecture and function. (A) Expression of connexin 43 (GJA1) mRNA, relative to that of undifferentiated hMSCs (assigned value 1, not shown) $(\mathrm{n}=6)$. (B) Percentage of $\mathrm{Cx} 43$-stained areas in cell condensates $(\mathrm{n} \geq 3)$.

(C) Representative confocal zprojections of $\mathrm{Cx} 43$ immunostaining (top) and the corresponding skeletonized images (bottom) revealing the branched architecture of the intercellular connectivity network. Scale bar $=40 \mu \mathrm{m}$. Zoomed-in sections for the skeletonized images of $\mathrm{S}_{0}$ and $\mathrm{S}_{90}$ highlighting the differences in the GJIC network. Scale bar $=3 \mu \mathrm{m}$. (D) Quantification of Cx43 architectural network connectivity from skeletonized images normalized against $\mathrm{Cx} 43$ in GJs ( $\mathrm{n} \geq 3$ ). (E) Representative confocal z-projections showing neurobiotin (NB) tracer (red) in the mesenchymal condensates and cell nuclei stained with Hoechst (blue). White lines represent measured distances of neurobiotin uptake. Scale bar $=80 \mu \mathrm{m}$. (F) Quantification of neurobiotin tracer uptake in day 6 condensates after $90 \mathrm{~s}$ exposure ( $\mathrm{n} \geq 24)$. Gray bars with green dots correspond to day 6 of chondrogenic induction; white bars with orange triangles correspond to day 9 . Results are given as individual sample values with the mean \pm SEM, ${ }^{*} p<0.05, * * p<0.01, * * * * p<0.0001$ 
314 Results showed an effect of local surface adhesiveness on the architecture and functionality of GJIC

315 networks in pre-cartilaginous cell condensates. However, it was unclear whether substrate adhesion is

316 relevant only at the beginning of condensation as a memory effect or if it continuously influences the

317 tissue as it forms. To consider these two possibilities, we designed a transplantation assay in which

318 condensates formed on $S_{90}$ and $S_{18}$, (the nanopatterns of highest and lowest ligand density) were collected

319 at day 3, plated on new $S_{90}$ and $S_{18}$ substrates and maintained for 3 more days in culture (Fig. 2A). The

320 percentage of area immunostained for $\mathrm{Cx} 43$ (GJ plaques) was assessed at day 6 for the transplanted and

321 non-transplanted condensates. Transplantation produced a significant boosting effect for condensates

322 plated on new $S_{90}$ substrates (Fig. 2B). In condensates transplanted from $S_{90}$ to fresh $S_{90}, C x 43$ production

323 increased by $71 \pm 21 \%$, while a $61 \pm 19 \%$ increase was observed for those transplanted from $S_{18}$.

324 Transplantation of either $S_{90}$ or $S_{18}$ condensates to fresh $S_{18}$ substrates did not render significant changes

325 in $\mathrm{Cx} 43$ production.

326 Condensates formed on one substrate and then transplanted to another will sense the new input only from

327 the side in direct contact with the new substrate. We questioned if effects derived from changing substrate

328 conditions would be confined to cells in direct contact with it (those at the basal layer of condensates) or

329 instead propagate to the middle and top layers of condensates. Transversal views of transplanted

330 condensates presented increased Cx43 production at all heights (Fig. 2C), showing that fresh substrate

331 inputs spread through cells and modulate protein expression within the whole forming tissue. Moreover,

332 the proportion of $\mathrm{Cx} 43$ production between the basal versus top regions was equal in control and

333 transplanted condensates, indicating that transplantation did not alter the ratios of protein distribution

334 among layers (Fig. 2D). 


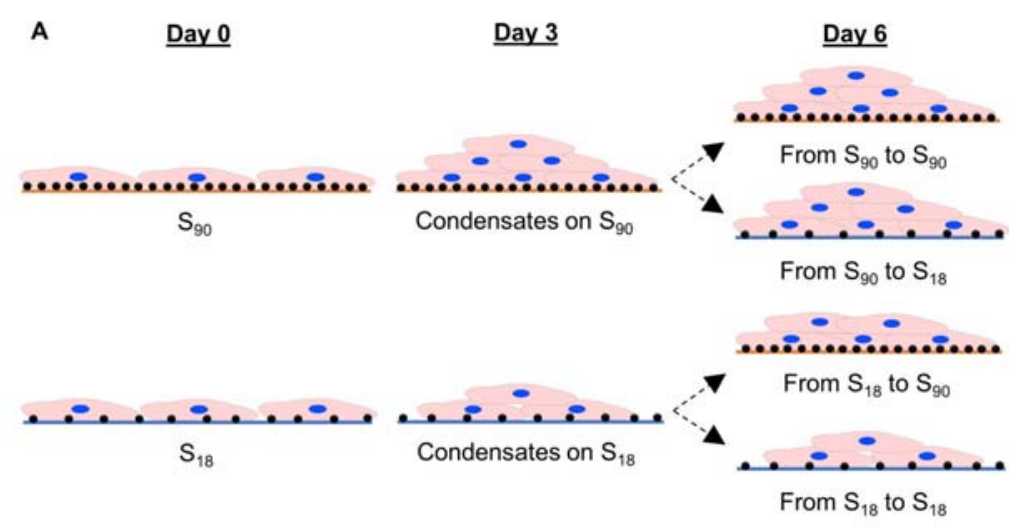

B

C

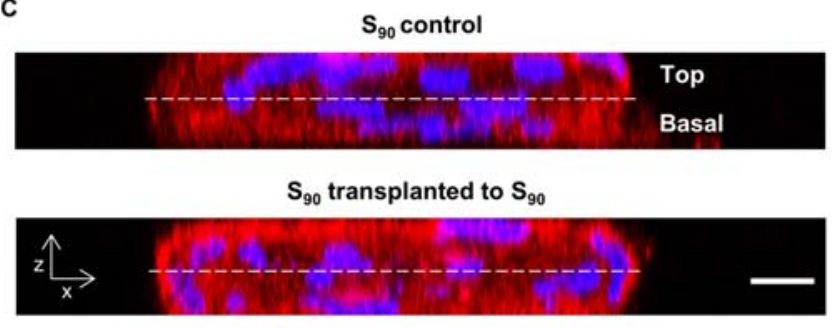

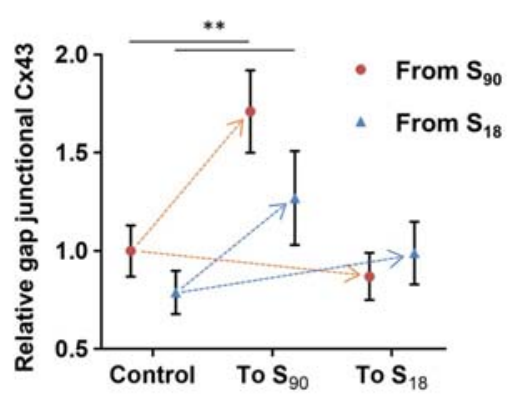

D

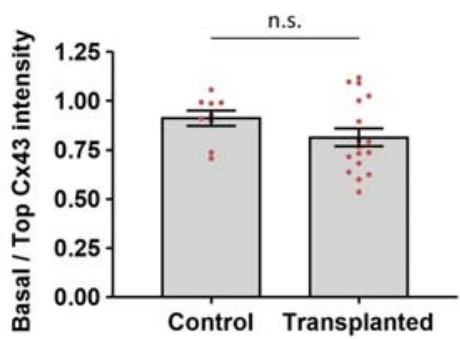

Fig. 2: Cell condensates adapt to changing ligand density. (A) Schematics of the transplantation experiment. Condensates formed on $S_{90}$ and $S_{18}$ substrates were collected at day 3 and plated on fresh $S_{90}$ or $\mathrm{S}_{18}$ substrates for 3 more days of chondrogenic induction. (B) Quantification of Cx43-stained percentage area for non-transplanted and transplanted condensates $(n \geq 7)$. (C) Confocal side views of control and transplanted $S_{90}$ condensates, stained for $\mathrm{Cx}_{43}$ (red) and Hoechst (blue). Substrate effect propagates to cells at all levels within condensates. Scale bar $=10 \mu \mathrm{m}$. (D) Ratio between $\mathrm{Cx}_{4} 43$ production at the basal and top regions of $S_{90}$ condensates in control $S_{90}$ substrates or transplanted to fresh $\mathrm{S}_{90}(\mathrm{n} \geq 9)$. Results are given as mean $\pm \mathrm{SEM}, * * p<0.01$ 


\subsection{Mechanism of substrate sensing and input propagation}

Integrin adhesions are the main mediators of cell-matrix adhesion and mechanical interactions [44,45]. To

346 evaluate their role in modulating GJIC on nanopatterns, we added RGD-functionalized dendrimers in

347 solution on formed condensates to block integrin receptors at the cell membrane. Disturbance of integrin

348 clustering at cell-substrate adhesion sites led to a $\mathrm{Cx} 43$ production decrease in $\mathrm{S}_{90}$ but not in $\mathrm{S}_{18}$ (Fig. 3A).

349 This indicates that integrin-mediated cell adhesion is responsible for the transduction and regulation of

350 substrate information that affects GJIC, and that cell response is triggered when integrins are engaged by

351 the RGD configuration provided by $\mathrm{S}_{90}$ nanopatterns.

352 Since perturbations at the cell membrane are transduced into chemical responses by propagation from

353 integrins through the cytoskeleton [16], we hypothesized that the substrate adhesion information

354 orchestrating GJIC during mesenchymal cell condensation propagates through the actin cortex. Cortical

355 actin assembly can be observed in early mesenchymal condensates [30]. Cortical tension gradients are

356 responsible for mesenchymal cell rearrangement during tissue formation and are essential in driving

357 tissue morphogenesis [46,47]. The cell cortex is formed by an actomyosin network, which is located

358 below the cell membrane. In the cortex, myosin-2 pulls on actin filaments and generates tension.

359 Inhibition of myosin-2 activity can cause a decrease in cortical tension of up to $80 \%$ [47]. Treatment of 6-

360 day condensates with the myosin-2 inhibitor blebbistatin decreased the percentage of area immunostained

361 for $\mathrm{Cx} 43$ of $\mathrm{S}_{90}$ condensates (Fig. 3A).

362 Adding dendrimers in solution affected cytoskeletal conformation in a similar manner as blebbistatin,

363 preventing polymerization and resulting in a diffuse distribution of actin in condensates, instead of 364 concentrating in clearly defined fibers as in control conditions (Fig. 3B). This shows that cytoskeletal 365 tension depends on integrin receptors engaging adherence sites at the substrates; we thus infer that cells at 366 the basal layer of condensates sense ligand inputs through integrins and propagate them by actin 367 contractility to adjacent cells (Fig. 3C). 

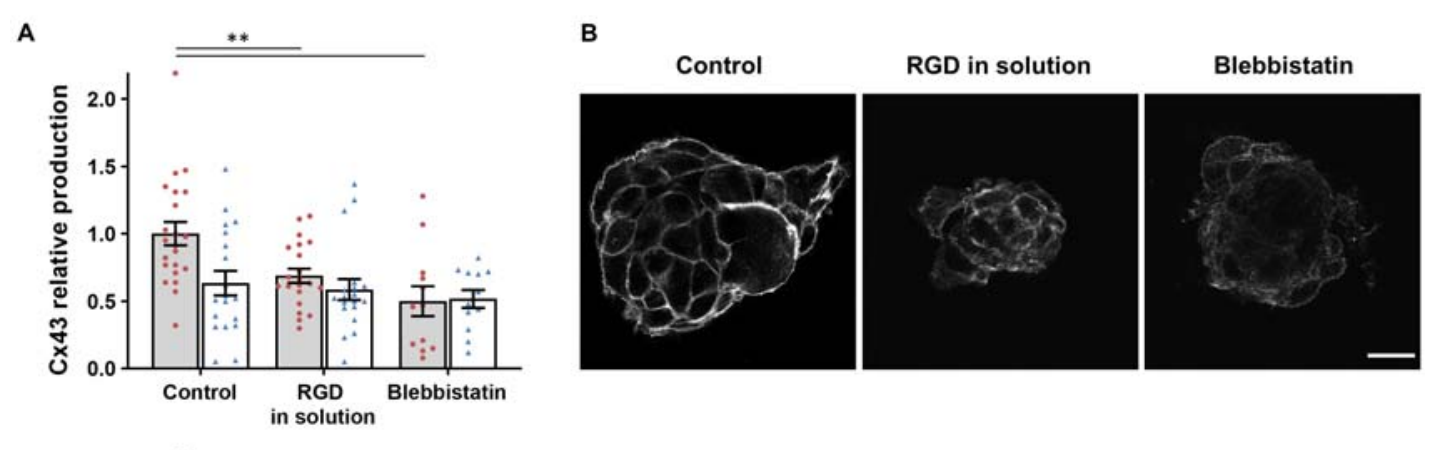

C

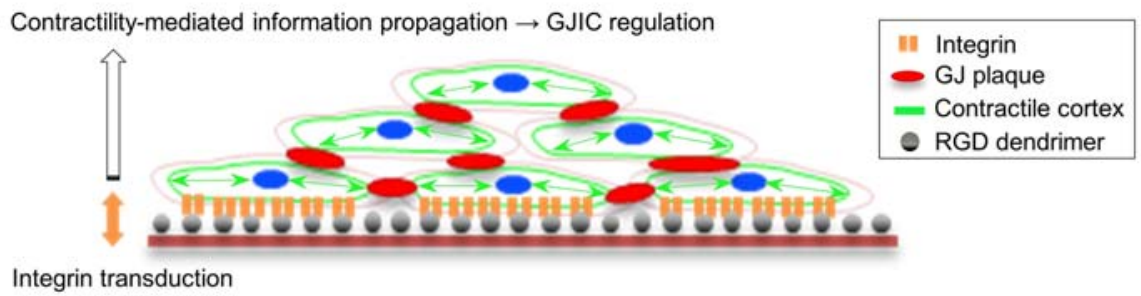

Fig. 3: Signal transduction and propagation. (A) Relative $C x 43$ production in $S_{90}$ (gray bars, red dots) block) or with blebbistatin (myosin inhibition). Scale bar $=25 \mu \mathrm{m}$. (C) Schematic representation of ligand density sensing through integrin adhesions, followed by actomyosin contraction-guided propagation of information in cell condensates.

\section{Discussion}

We studied the effects of ECM adhesion in the establishment of GJIC during mesenchymal cell condensation, a prevalent morphogenetic transition. To this end, we used previously developed RGD dendrimer-based nanopatterns of tunable local surface adhesiveness [29,30]. Larger and more stable cell condensates are obtained on $S_{90}$ nanopatterns, with cells packed closer together.

We analyzed the influence of substrate ligand density on the establishment of a gap junction intercellular communication (GJIC) network in cell condensates. We measured gene expression and assembly at gap junctions of $\mathrm{Cx} 43$, a connexin which is ubiquitously expressed in developing cartilage $[39,48]$. We found $\mathrm{Cx} 43$ increased with local surface adhesiveness in the nanopatterns, a similar interdependence to what we observed previously for the focal adhesion adaptor protein paxillin [30]. This is in agreement with Zhou et $a l$., who observed a direct interaction between FAK and paxillin with $\mathrm{Cx} 43$ in cells from the human apical papilla, which depended on substrate compliance [13]. In our case, cell condensates on $S_{90}$ nanopatterns 
presented increased $\mathrm{Cx} 43$ expression with a higher protein turnover rate, revealing a direct effect of substrate ligand density on gap junction protein regulation.

We analyzed the architectural connectivity of $\mathrm{Cx} 43$ in condensates to assess whether substrate ligand density modulates the development of gap junction networks beyond protein expression. We found that $\mathrm{S}_{90}$ condensates contain a $\mathrm{Cx} 43$ architecture that is more intricate, with less end-point voxels and shorter branches, indicative of improved communication capacities. Moreover, a tracer uptake assay revealed that GJIC is more efficient on $S_{90}$ condensates. This shows that local surface adhesiveness given by the nanopattern configuration determines not only protein expression but also its spatial disposition during morphogenesis, affecting the functionality of the forming tissue. Given that $S_{90}$ substrates also promote cell differentiation towards chondrocytes [30], we conclude that nanopatterning at this particular ligand density improves cartilage formation in vitro.

A condensate transplantation assay was designed to test whether cells in the condensate, previously in contact with the substrate during cell recruitment, retain initial substrate information (memory effect) or receive a continuous feedback of substrate input. Transplantation of cell condensates to a new $S_{90}$ substrate caused a significant increase in $\mathrm{Cx} 43$, suggesting that cell condensates still preserve a certain level of mesenchymal plasticity at early stages of chondrogenic differentiation [49], thereby allowing phenotype reconfiguration in response to the ECM input. No effects were observed for transplantation to $\mathrm{S}_{18}$ substrates.

407 Effects of substrate transplantation on Cx43 expression were observed at all heights within condensates and transplanted condensates maintained the proportion of total protein contained at the basal and top regions, indicating that substrate inputs are propagated into the third dimension, across cells to the top. These results show that changing environmental conditions during morphogenesis continually modulate the characteristics of forming tissue, pointing to the importance of accounting for time variations in the

412 design of experimental setups for development studies, as well as biomaterials for tissue engineering.

413 Finally, we addressed the biological mechanism by which cells sense substrate ligand density and 414 propagate it into condensates. Blocking integrin-mediated interactions between the substrate and the basal

415 layer in cell condensates caused a $\mathrm{Cx} 43$ decrease in $\mathrm{S}_{90}$ but not in $\mathrm{S}_{18}$. This observation, together with 416 results of condensate stability and GJIC, demonstrates that the establishment of GJIC during 417 mesenchymal condensation is an adhesion-gated mechanism, in which $\mathrm{S}_{90}$ nanopattern configuration 418 provides optimal ligand density and distribution to trigger cell response.

419 To investigate the propagation of substrate information within cell condensates, an inhibition experiment 420 for myosin-2 was conducted. Inhibition of myosin-2 activity by blebbistatin caused a decrease of Cx43 in $421 \mathrm{~S}_{90}$ cell condensates, in agreement with previous reports [50]. This indicates that once integrins are 422 engaged, the adhesion information from the substrate is transduced and propagates through the actin 

Results agree with those from Gowrishankar et al., who predicted that the dynamics of membrane proteins are regulated by the cell cortex [51]. Therefore, we propose a contractility-based mechanism for the propagation of ECM adhesion information within the condensates in which local substrate adhesiveness induces a rearrangement and adaptation of the actin cortex and cell-cell junctions in the first cell layers [52,53] and propagates through the tissue by myosin-2-mediated cortex contractions, regulating Cx43 dynamics during the mesenchymal condensation process (Fig. 3C).

Our findings clearly reflect the impact that the fine tuning of materials interfaces has in cell response. By tailoring the nanopattern configuration of the cell-adhesive motif RGD, we exerted control over the architecture and function of a complex dynamic biological system. The results have an immediate application to cartilage in vitro engineering [30,54], but they are also extensible to the study of other biological processes in which active ECM remodelling and thus, changes in the adhesion requirements and intercellular communication play an active role, such as in cancer progression [55].

\section{CRediT author statement}

438 I. Casanellas: Conceptualization, Methodology, Investigation, Formal analysis, Writing - Original Draft, Visualization. A. Lagunas: Conceptualization, Methodology, Formal analysis, Writing - Original Draft, Supervision, Project administration, Funding acquisition. Y. Vida: Methodology, Resources (design and production of RGD-functionalized dendrimers), Writing - Review \& Editing. E. Pérez-Inestrosa: (RT-qPCR), Writing - Review \& Editing. J. Magalhaes: Methodology (RT-qPCR), Supervision, Writing - Review \& Editing. J. A. Andrades: Writing - Review \& Editing, Funding acquisition. J. Becerra: Writing - Review \& Editing, Funding acquisition. J. Samitier: Conceptualization, Methodology, Writing - Review \& Editing, Supervision, Project administration, Funding acquisition.

\section{Funding}

This work was supported by the Biomedical Research Networking Center (CIBER), Spain. CIBER is an initiative funded by the VI National R\&D\&i Plan 2008-2011, Iniciativa Ingenio 2010, Consolider Program, CIBER Actions, and the Instituto de Salud Carlos III (RD16/0006/0012; RD16/0011/0022), with the support of the European Regional Development Fund (ERDF). This work was funded by the

454 CERCA Program and by the Commission for Universities and Research of the Department of Innovation, 455 Universities, and Enterprise of the Generalitat de Catalunya (2017 SGR 1079). This work has been 456 developed in the context of the AdvanceCat project (COMRDI15-1-0013) with the support of ACCIÓ 
457

458

459

460

461

462

463

464

465

466

467

468

469

470

471

472

473

474

475

476

477

478

479

480

481

482

483

484

485

486

487

488

489

490

(Catalonia Trade and Investment; Generalitat de Catalunya) under the Catalonian ERDF operational program 2014-2020. This work was funded by the Spanish Ministry of Economy and Competitiveness (MINECO) through the projects MINDS (Proyectos I+D Excelencia + FEDER): TEC2015-70104-P-P and BIOBOT (Programa Explora Ciencia / Tecnología): TEC2015- 72718-EXP, as well as the Spanish Ministry of Science and Education (PID2019-104293GB-I00), and the Consejería de Salud, Junta de Andalucía (UMA18-FEDERJA-007; UMA18 $\square$ FEDERJA $\square$ 133). The authors further acknowledge funds from the INTERREG V cooperation program for Spain-Portugal (POCTEP) 2014-2020 project (0245_IBEROS_1_E). I. C. acknowledges support from MINECO through the Subsidies for Predoctoral Contracts for the Training of Doctors open call, co-funded by the European Social Fund (2016), grant number: BES-2016-076682. C. R-P. acknowledges support from i-PFIS Doctoral Program (IFI15/00151) funded by ISCIII.

\section{Conflicts of interest}

There are no conflicts to declare.

\section{Acknowledgements}

We thank N. Montserrat for help with the transplantation assay, R. Paoli for producing Video S1, and P. Roca-Cusachs for the fruitful discussions.

\section{References}

[1] A.M. DeLise, L. Fischer, R.S. Tuan, Cellular interactions and signaling in cartilage development, Osteoarthr. Cartil. 8 (2000) 309-334. https://doi.org/10.1053/joca.1999.0306.

[2] H. Grüneberg, The pathology of development: a study of inherited skeletal disorders in animals, Blackwells Scientific Publications, Oxford, 1963.

[3] S. Christley, M.S. Alber, S.A. Newman, Patterns of mesenchymal condensation in a multiscale, discrete stochastic model, PLoS Comput. Biol. 3 (2007) 743-753. https://doi.org/10.1371/journal.pcbi.0030076.

[4] P. Singh, J.E. Schwarzbauer, Fibronectin and stem cell differentiation - lessons from chondrogenesis, J. Cell Sci. 125 (2012) 3703-3712. https://doi.org/10.1242/jcs.095786.

[5] C.N.D. Coelho, R.A. Kosher, Gap junctional communication during limb cartilage differentiation, Dev. Biol. 144 (1991) 47-53. https://doi.org/https://doi.org/10.1016/0012-1606(91)90477-K.

[6] J.C. Hervé, M. Derangeon, Gap-junction-mediated cell-to-cell communication, Cell Tissue Res. 352 (2013) 21-31. https://doi.org/10.1007/s00441-012-1485-6. 
491

492

493

494

495

496

497

498

499

500

501

502

503

504

505

506

507

508

509

510

511

512

513

514

515

516

517

518

519

520

521

522

523

524

[7] J.C. Hervé, M. Derangeon, D. Sarrouilhe, B.N.G. Giepmans, N. Bourmeyster, Gap junctional channels are parts of multiprotein complexes, Biochim. Biophys. Acta - Biomembr. 1818 (2012) 1844-1865. https://doi.org/10.1016/j.bbamem.2011.12.009.

[8] M.D. Mayan, R. Gago-Fuentes, P. Carpintero-Fernandez, P. Fernandez-Puente, P. FilgueiraFernandez, N. Goyanes, V. Valiunas, P.R. Brink, G.S. Goldberg, F.J. Blanco, Articular chondrocyte network mediated by gap junctions: Role in metabolic cartilage homeostasis, Ann. Rheum. Dis. 74 (2015) 275-284. https://doi.org/10.1136/annrheumdis-2013-204244.

[9] H.J. Donahue, R.W. Qu, D.C. Genetos, Joint diseases: From connexins to gap junctions, Nat. Rev. Rheumatol. 14 (2018) 42-51. https://doi.org/10.1038/nrrheum.2017.204.

[10] P.D. Lampe, B.P. Nguyen, S. Gil, M. Usui, J. Olerud, W.G. Carter, Y. Takada, Cellular interaction of integrin $\alpha 3 \beta 1$ with laminin 5 promotes gap junctional communication, J. Cell Biol. 143 (1998) 1735-1747. https://doi.org/10.1083/jcb.143.6.1735.

[11] N. Batra, S. Burra, A.J. Siller-Jackson, S. Gu, X. Xia, G.F. Weber, D. DeSimone, L.F. Bonewald, E.M. Lafer, E. Sprague, M.A. Schwartz, J.X. Jiang, Mechanical stress-activated integrin $\alpha 5 \beta 1$ induces opening of connexin 43 hemichannels, Proc. Natl. Acad. Sci. 109 (2012) 3359-3364. https://doi.org/10.1073/pnas.1115967109.

[12] A.E. Zemljic-Harpf, J.C. Godoy, O. Platoshyn, E.K. Asfaw, A.R. Busija, A.A. Domenighetti, R.S. Ross, Vinculin directly binds zonula occludens- 1 and is essential for stabilizing connexin-43containing gap junctions in cardiac myocytes, J. Cell Sci. 127 (2014) 1104-1116. https://doi.org/10.1242/jcs.143743.

[13] C. Zhou, D. Zhang, W. Du, J. Zou, X. Li, J. Xie, Substrate mechanics dictate cell-cell communication by gap junctions in stem cells from human apical papilla, Acta Biomater. 107 (2020) 178-193. https://doi.org/10.1016/j.actbio.2020.02.032.

[14] B.M. Gumbiner, Cell adhesion: The molecular basis of tissue architecture and morphogenesis, Cell. 84 (1996) 345-357. https://doi.org/10.1016/S0092-8674(00)81279-9.

[15] J.T. Parsons, A.R. Horwitz, M.A. Schwartz, Cell adhesion: Integrating cytoskeletal dynamics and cellular tension, Nat. Rev. Mol. Cell Biol. 11 (2010) 633-643. https://doi.org/10.1038/nrm2957.

[16] M. Bachmann, S. Kukkurainen, V.P. Hytönen, B. Wehrle-Haller, Cell adhesion by integrins, Physiol. Rev. 99 (2019) 1655-1699. https://doi.org/10.1152/physrev.00036.2018.

[17] D.C. Van Essen, A tension-based theory of morphogenesis and compact wiring in the central nervous system, Nature. 385 (1997) 313-318. https://doi.org/10.1038/385313a0.

[18] M. Tada, M.L. Concha, Vertebrate gastrulation: Calcium waves orchestrate cell movements, Curr. Biol. 11 (2001) 470-472. https://doi.org/10.1016/S0960-9822(01)00284-6.

[19] Hung Ping Shih, D. Panlasigui, V. Cirulli, M. Sander, ECM signaling regulates collective cellular 
dynamics to control pancreas branching morphogenesis, Cell Rep. 14 (2016) 169-179. https://doi.org/10.1016/j.celrep.2015.12.027.

[20] F. Jiang, H. Hörber, J. Howard, D.J. Müller, Assembly of collagen into microribbons: Effects of pH and electrolytes, J. Struct. Biol. 148 (2004) 268-278. https://doi.org/10.1016/j.jsb.2004.07.001.

[21] M.L. Smith, D. Gourdon, W.C. Little, K.E. Kubow, R.A. Eguiluz, S. Luna-Morris, V. Vogel, Force-induced unfolding of fibronectin in the extracellular matrix of living cells, PLoS Biol. 5 (2007) 2243-2254. https://doi.org/10.1371/journal.pbio.0050268.

[22] W.C. Little, M.L. Smith, U. Ebneter, V. Vogel, Assay to mechanically tune and optically probe fibrillar fibronectin conformations from fully relaxed to breakage, Matrix Biol. 27 (2008) 451461. https://doi.org/10.1016/j.matbio.2008.02.003.

[23] M.F. Garcia-Parajo, A. Cambi, J.A. Torreno-Pina, N. Thompson, K. Jacobson, Nanoclustering as a dominant feature of plasma membrane organization, J. Cell Sci. 127 (2014) 4995-5005. https://doi.org/10.1242/jcs.146340.

[24] M. Arnold, E.A. Cavalcanti-Adam, R. Glass, J. Blümmel, W. Eck, M. Kantlehner, H. Kessler, J.P. Spatz, Activation of integrin function by nanopatterned adhesive interfaces, ChemPhysChem. 5 (2004) 383-388. https://doi.org/10.1002/cphc.200301014.

[25] E.A. Cavalcanti-Adam, T. Volberg, A. Micoulet, H. Kessler, B. Geiger, J.P. Spatz, Cell spreading and focal adhesion dynamics are regulated by spacing of integrin ligands, Biophys. J. 92 (2007) 2964-2974. https://doi.org/10.1529/biophysj.106.089730.

[26] J.A. Deeg, I. Louban, D. Aydin, C. Selhuber-Unkel, H. Kessler, J.P. Spatz, Impact of local versus global ligand density on cellular adhesion, Nano Lett. 11 (2011) 1469-1476. https://doi.org/10.1021/n1104079r.

[27] R. Oria, T. Wiegand, J. Escribano, A. Elosegui-Artola, J.J. Uriarte, C. Moreno-Pulido, I. Platzman, P. Delcanale, L. Albertazzi, D. Navajas, X. Trepat, J.M. García-Aznar, E.A. Cavalcanti-Adam, P. Roca-Cusachs, Force loading explains spatial sensing of ligands by cells, Nature. 552 (2017) 219224. https://doi.org/10.1038/nature24662.

[28] A. Lagunas, D. Caballero, J. Samitier, Influence of Controlled Micro $\square$ and Nanoengineered Environments on Stem Cell Fate, in: A. Tiwari, B. Garipcan, L. Uzun (Eds.), Adv. Surfaces Stem Cell Res., 1st ed., Hoboken: Wiley, 2016: pp. 87-141.

[29] A. Lagunas, A.G. Castaño, J.M. Artés, Y. Vida, D. Collado, E. Pérez-Inestrosa, P. Gorostiza, S. Claros, J.A. Andrades, J. Samitier, Large-scale dendrimer-based uneven nanopatterns for the study of local arginine-glycine-aspartic acid (RGD) density effects on cell adhesion, Nano Res. 7 (2014) 399-409. https://doi.org/10.1007/s12274-014-0406-2.

[30] A. Lagunas, I. Tsintzou, Y. Vida, D. Collado, E. Pérez-Inestrosa, C. Rodríguez Pereira, J. 
Magalhaes, J.A. Andrades, J. Samitier, Tailoring RGD local surface density at the nanoscale toward adult stem cell chondrogenic commitment, Nano Res. 10 (2017) 1959-1971. https://doi.org/10.1007/s12274-016-1382-5.

[31] I. Casanellas, A. Lagunas, I. Tsintzou, Y. Vida, D. Collado, E. Pérez-Inestrosa, C. RodríguezPereira, J. Magalhaes, P. Gorostiza, J.A. Andrades, J. Becerra, J. Samitier, Dendrimer-based uneven nanopatterns to locally control surface adhesiveness: A method to direct chondrogenic differentiation, J. Vis. Exp. 131 (2018). https://doi.org/10.3791/56347.

[32] I. Casanellas, A. Lagunas, Y. Vida, E. Pérez-Inestrosa, J.A. Andrades, J. Becerra, J. Samitier, Matrix nanopatterning regulates mesenchymal differentiation through focal adhesion size and distribution according to cell fate, Biomimetics. 4 (2019). https://doi.org/10.3390/biomimetics4020043.

[33] B.E. Bobick, F.H. Chen, A.M. Le, R.S. Tuan, Regulation of the chondrogenic phenotype in culture, Birth Defects Res. Part C - Embryo Today Rev. 87 (2009) 351-371. https://doi.org/10.1002/bdrc.20167.

[34] I. Horcas, R. Fernández, J.M. Gómez-Rodríguez, J. Colchero, J. Gómez-Herrero, A.M. Baro, WSXM: A software for scanning probe microscopy and a tool for nanotechnology, Rev. Sci. Instrum. 78 (2007). https://doi.org/10.1063/1.2432410.

[35] D.G. Uitenbroek, SISA Binomial, (1997). http://www.quantitativeskills.com/sisa/statistics/ttest.htm (accessed January 30, 2020).

[36] Y. Zhu, C. Gao, X. Liu, T. He, J. Shen, Immobilization of Biomacromolecules onto Aminolyzed Poly(L-lactic acid) toward Acceleration of Endothelium Regeneration, Tissue Eng. 10 (2004) 5361. https://doi.org/10.1089/107632704322791691. role of adhesion in chondrogenesis, Int. J. Mol. Sci. 21 (2020) 5269. https://doi.org/10.3390/ijms21155269.

[38] T.M. Ribeiro-Rodrigues, T. Martins-Marques, S. Morel, B.R. Kwak, H. Girão, Role of connexin 43 in different forms of intercellular communication - gap junctions, extracellular vesicles and tunnelling nanotubes, J. Cell Sci. 130 (2017) 3619-3630. https://doi.org/10.1242/jcs.200667.

591 [40] J.M. Rhett, J. Jourdan, R.G. Gourdie, Connexin 43 connexon to gap junction transition is regulated by zonula occludens-1, Mol. Biol. Cell. 22 (2011) 1516-1528. https://doi.org/10.1091/mbc.E10- 
06-0548.

594 [41] E. Leithe, S. Sirnes, T. Fykerud, A. Kjenseth, E. Rivedal, Endocytosis and post-endocytic sorting of connexins, Biochim. Biophys. Acta - Biomembr. 1818 (2012) 1870-1879. https://doi.org/10.1016/j.bbamem.2011.09.029.

[42] M. Piehl, C. Lehmann, A. Gumpert, J.-P. Denizot, D. Segretain, M.M. Falk, Internalization of Large Double-Membrane Intercellular Vesicles by a Clathrin-dependent Endocytic Process, Mol. Biol. Cell. 18 (2007) 337-347. https://doi.org/10.1091/mbc.E06.

[44] Z. Sun, S.S. Guo, R. Fässler, Integrin-mediated mechanotransduction, J. Cell Biol. 215 (2016) 445-456.

605

[45] J.Z. Kechagia, J. Ivaska, P. Roca-Cusachs, Integrins as biomechanical sensors of the microenvironment, Nat. Rev. Mol. Cell Biol. (2019). https://doi.org/10.1038/s41580-019-0134-2.

[46] M. Nishikawa, S.R. Naganathan, F. Jülicher, S.W. Grill, Controlling contractile instabilities in the actomyosin cortex, Elife. 6 (2017) 1-21. https://doi.org/10.7554/eLife.19595.

[47] H. Tao, M. Zhu, K. Lau, O.K.W. Whitley, M. Samani, X. Xiao, X.X. Chen, N.A. Hahn, W. Liu, M. Valencia, M. Wu, X. Wang, K.D. Fenelon, C.C. Pasiliao, D. Hu, J. Wu, S. Spring, J. Ferguson, E.P. Karuna, R.M. Henkelman, A. Dunn, H. Huang, H.Y.H. Ho, R. Atit, S. Goyal, Y. Sun, S. murine mandibular arch, Nat. Commun. 10 (2019) 1-18. https://doi.org/10.1038/s41467-01909540-z.

[48] R.A. Meyer, M.F. Cohen, S. Recalde, J. Zakany, S.M. Bell, W.J.J. Scott, C.W. Lo, Developmental regulation and asymmetric expression of the gene encoding $\mathrm{Cx} 43$ gap junctions in the mouse limb bud., Dev. Genet. 21 (1997) 290-300. https://doi.org/10.1002/(SICI)15206408(1997)21:4<290::AID-DVG6>3.0.CO;2-2. Reacquisition of Primitive Phenotype in Human Mesenchymal Stem Cell Aggregates, Stem Cells. 35 (2017) 398-410. https://doi.org/10.1002/stem.2510.

[50] S. Olk, G. Zoidl, R. Dermietzel, Connexins, cell motility, and the cytoskeleton, Cell Motil. Cytoskeleton. 66 (2009) 1000-1016. https://doi.org/10.1002/cm.20404.

[51] K. Gowrishankar, S. Ghosh, S. Saha, C. Rumamol, S. Mayor, M. Rao, Active remodeling of cortical actin regulates spatiotemporal organization of cell surface molecules, Cell. 149 (2012) 1353-1367. https://doi.org/10.1016/j.cell.2012.05.008. 
627 [52] N. Wang, J.D. Tytell, D.E. Ingber, Mechanotransduction at a distance: Mechanically coupling the

628 extracellular matrix with the nucleus, Nat. Rev. Mol. Cell Biol. 10 (2009) 75-82.

629 https://doi.org/10.1038/nrm2594.

630 [53] P. Chugh, E.K. Paluch, The actin cortex at a glance, J. Cell Sci. 131 (2018) 1-9.

631 https://doi.org/10.1242/jcs.186254.

632 [54] C. Rodríguez-Pereira, A. Lagunas, I. Casanellas, Y. Vida, E. Pérez-Inestrosa, J.A. Andrades, J.

633

634 Becerra, J. Samitier, F.J. Blanco, J. Magalhães, RGD-dendrimer-poly(L-lactic) acid nanopatterned substrates for the early chondrogenesis of human mesenchymal stromal cells derived from osteoarthritic and healthy donors, Materials (Basel). 13 (2020).

637 https://doi.org/10.3390/ma13102247.

638

[55] C. Bonnans, J. Chou, Z. Werb, Remodelling the extracellular matrix in development and disease, Nat. Rev. Mol. Cell Biol. 15 (2014) 786-801. https://doi.org/10.1038/nrm3904. 
A

GJA1

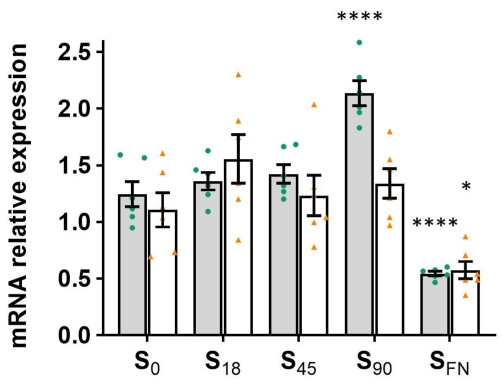

B

Cx43 in gap junctions
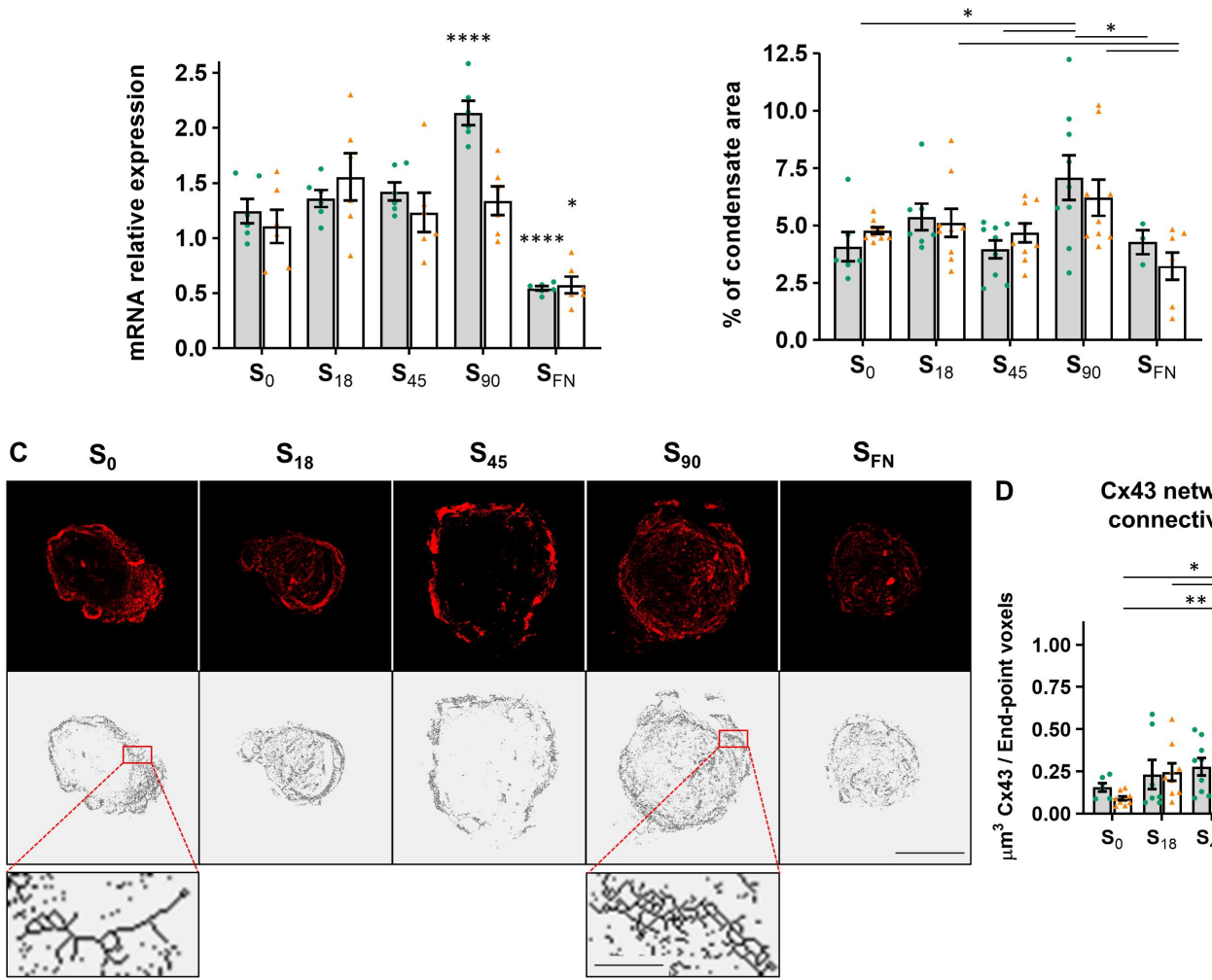

\section{Cx43 network connectivity}

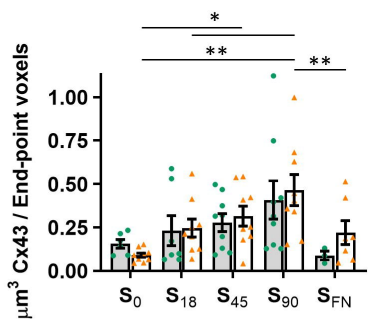

E $\quad \mathrm{S}_{0}$

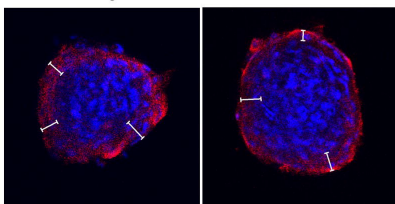

$\mathrm{S}_{45}$

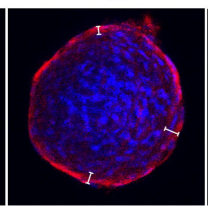

$\mathrm{S}_{\mathrm{FN}}$

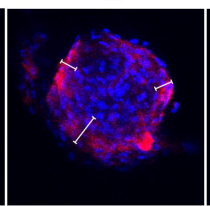

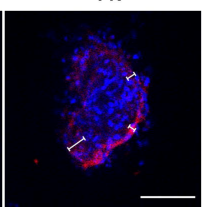

F

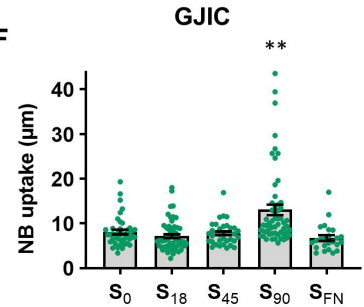


A

Day 0

Day 3

Day 6

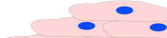

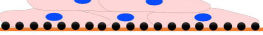

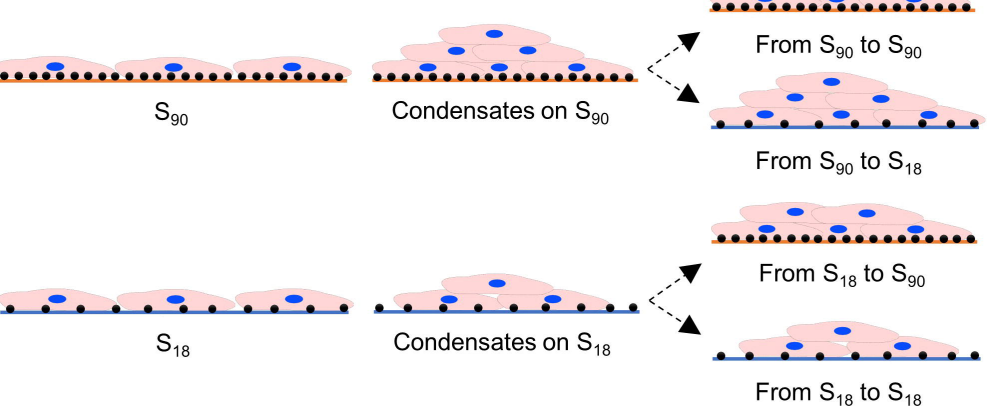

C

$$
\mathrm{S}_{90} \text { control }
$$

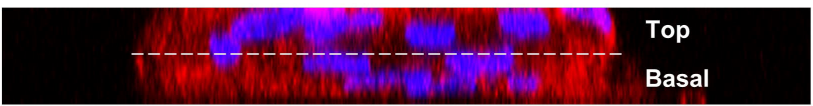

$S_{90}$ transplanted to $S_{90}$

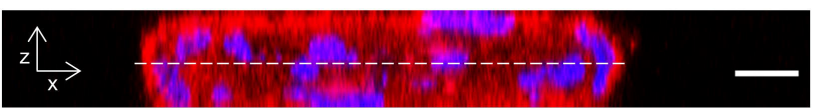

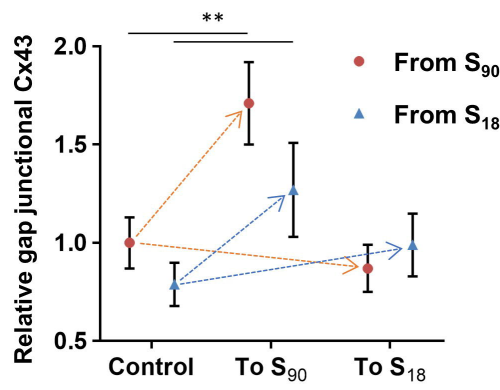

D

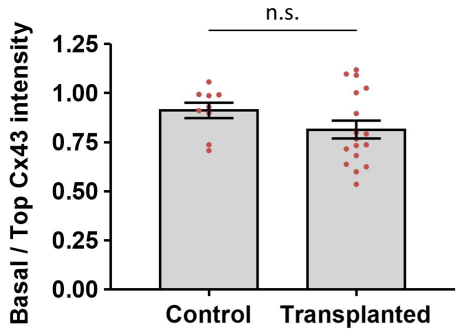


A

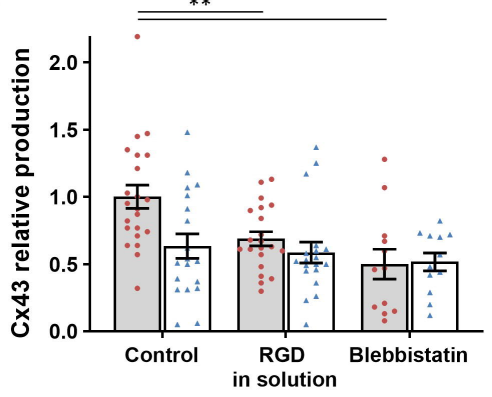

B

\section{Control}

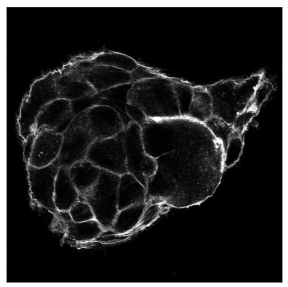

RGD in solution

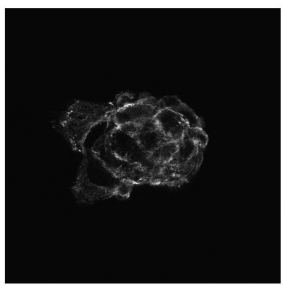

Blebbistatin

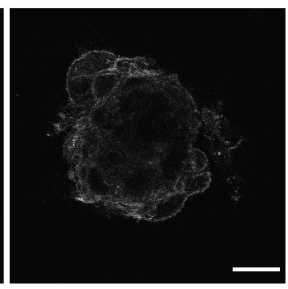

C

Contractility-mediated information propagation $\rightarrow$ GJIC regulation

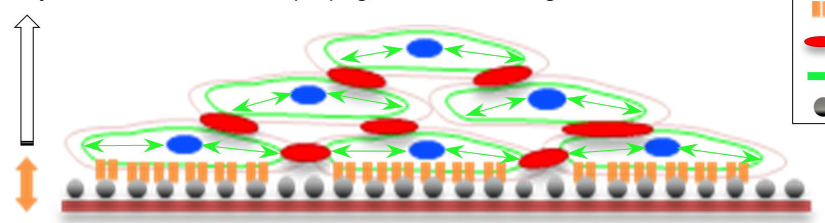

III. Integrin

- GJ plaque

- Contractile cortex RGD dendrimer

Integrin transduction 